\author{
Acta Technologica Agriculturae 1 \\ Nitra, Slovaca Universitas Agriculturae Nitriae, 2019, pp. 12-16
}

\title{
CHOOSING A PROPER MAINTENANCE AND REPAIR STRATEGY FOR TRACTORS (IN URMIA)
}

\author{
Razieh POURDARBANI \\ University of Mohaghegh Ardabili, Ardabil, Iran
}

\begin{abstract}
Maintenance plays an important role in reliability, availability, production quality, risk reduction, efficiency increasing, equipment security, etc. Therefore, maintenance strategies have a special position in industry. Simultaneously, effect of tractor power is considerable in agriculture; therefore, it is necessary to pay attention to the probability of failure, repair time and causes of malfunctioning. Many variables, including cost, depreciation, breakdowns, annual performance, etc., have major impact on tselection of a maintenance strategy. Therefore, these variables were determined with the help of experts. Subsequently, these were clustered into several main criteria groups on the basis of factor analysis using SPSS software. Obtained results were used in a hierarchical structure to suggest the most appropriate maintenance strategy based on pair-wise comparison. According to the regional conditions and available facilities, results showed that the proactive maintenance strategy proved to be the best suggested option from four maintain strategies, namely emergency maintenance, proactive maintenance, preventive maintenance, predictive maintenance.
\end{abstract}

Keywords: maintenance strategy; factor analysis; analytical hierarchical process

As agricultural industry is rapidly expanding and it will have to compete with large companies in near future, managers should be prepared to adapt to new management systems, including maintenance management in order to achieve the best efficiency and reliability. In fact, prediction of the exact time of failures and their repairs can lead to a reduction in the cost of repairs and time delays in the machinery operation, more efficient planning, higher safety, increase in financial savings and higher economic returns (Khodabakhshian et al., 2008). In Iran, repairs and replacement costs show a relatively high figure in terms of global standards. In order to automate the production in the agricultural sector, reducing these costs can significantly help to the proper operation of machines and eliminate the disadvantages (Jafari and Mahvi Diani, 2003). Maintenance is usually referred to as all activities that must be performed to ensure the reliability and operation of a device and minimize the number of sudden failures (Bartholomew, 1981; Zasadzień and Midor, 2018). This approach has gradually been introduced into the industry since the 1970s (Dahunsi, 2008).

Maintenance methods that have been invented over the past years include: (a) non-programmed system, in which the repairs take place after the system is stopped and emergency repairs are necessary, and (b) programmed systems, in which an earlier schedule for maintenance and repair activities is developed. Main purpose of these systems is to prevent emergency repairs and unexpected stops. It includes sub-systems, namely proactive maintenance (PAM), preventive maintenance (PM) and predictive maintenance (PDM). Preventive maintenance (PM) focuses its policy on pre-failure repairs, and is particularly suited to industries with high sensitivity to process changes and unplanned changes to the system. It provides appropriate instructions for periodic maintenance or replacement of parts particularly in the case of continuous and mass production systems (Shirmohammadi, 2002). Predictive maintenance (PDM) is a graphical process for detecting, analysing and repairing equipment problems before failure. In fact, existence of weaknesses as such increases preventive maintenance activity and prompts the users to check instantaneously the condition of the equipment from the point of view of temperature, pressure, and other factors by installing measuring equipment and with the help of the software. Installation of such systems is expensive and frequently comes with complex equipment and it is questionable whether the degree of process sensitivity can justify the utilization of such systems. Proactive maintenance (PAM) prevents the source of failure from developing by modifying the conditions that could lead to the destruction of the system. In such manner, it can ensure high reliability, pro-long the life of mechanical equipment and avoid critical failures.

Behzad et al. (2007) performed measurements of vibrations at appropriate locations and evaluated the process of these vibrations and their frequency spectra at water pumping stations with a predictive maintenance approach. Taking into account that obtained frequency spectra were indicative of defect type, defects were detected before the critical state occurred and repairs were performed. Mirzakhani (2004) conducted a study on 
vibration analysis as a foundation for proactive maintenance in cement company. As time went by, it was noted that average vibrations of devices were reduced. However, these vibrations sometimes increased due to no particular reason. After performing the necessary repairs and adjustments, vibration parameters were reduced again. Afsharnia et al. (2013) studied the effect of maintenance policies on failure rate of various systems in the Messier Ferguson 399 tractor in Khuzestan by means of a questionnaire and direct interviews in five province zones. Regression analysis, carried out using the exponential function estimation, revealed that different tractors, which were repaired in the past, showed significant signs of wear. Tractors subjected to preventive maintenance, however, also showed severe wear - their engine and steering were past their service life; hydraulic system and cooling were at the end of their service life and at the brink of burnout phase; power system and power transmission system were in phase of initial failures; brake and fuel systems were at the end of the life cycle, which would quite likely develop to the burnout phase. Say and Sumer (2011) conducted a study on the analysis of the linear degradation rate of compound planter and came to conclusion that breakdowns were largely influenced by annual operating hours, maintenance policies and work environment. Mousavi Pour et al. (2012) examined the condition of sugar cane harvesting machines and methods for their maintenance and repair, emphasizing oil status monitoring method. Results showed that use of oil status monitoring method resulted in reduction of malfunctions by $22 \%$ in standby machines and by $13 \%$ in refurbished machines in comparison to emergency maintenance strategy. Exner et al. (2017) conducted a research on proactive maintenance as success factor for use-oriented Product-Service Systems. In use-oriented Product-Service Systems (PSS), ownership of the product remains with the provider who is responsible for maintenance, repair and overhaul. Therefore, risk of machine unavailability is transferred from the customer to the PSS provider. In order to minimize this risk, the provider needs to reduce unscheduled downtimes to enhance machine availability. Hence, proactive maintenance is an important success factor for providing this PSS type.

Currently, Urmia's maintenance system is based on an emergency strategy. Selection of this strategy in the past was due to the lack of familiarity with the premature costs of operations caused by stagnation and stopping of the machine. However, adequate maintenance policy is vital for the mass production and reduction of stops in production is essential for it. However, one of the primary questions in managing and adopting to a new management system is to decide and select the appropriate option from the existing strategies. We tried to select appropriate strategy for the existing facilities and capital in this paper.

\section{Material and methods}

This research was conducted in Urmia in 2016. In order to select the most adequate maintenance strategy for the mechanization service companies, firstly, it is necessary to identify the factors affecting the maintenance techniques. These factors were determined by experts, including representatives from technical departments, repair shops, dealers and service companies. Due to the large number of criteria, it was necessary to select a statistical method for summarizing the data, which would convert the criteria to sub criteria called factors, with help of factor analysis in SPSS Statistics 23. First of all, it selects a combination of variables, correlations of which show the highest amount of variance observed; this sets factor 1 . Factor 2 is a set of variables that has the highest contribution in explaining the remaining variance. This method is also applied for the third, fourth, and subsequent factors, so that all variables can be clustered (Fig. 1).

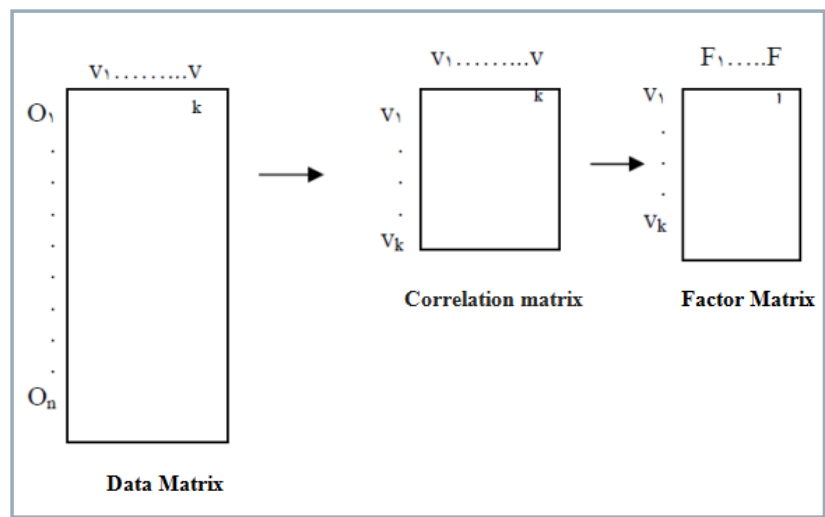

Fig. 1 Data transfer to clusters

If $Y_{i}$ is the observed variable and $F 1$ and $F 2$ are two effective factors, mathematical expression of the factor analysis can be written as follows (Richards, 1983):

$$
\begin{gathered}
Y_{i}=\lambda_{i 1} F_{1}+\lambda_{i 2} F_{2}+(1) e_{i} \\
\operatorname{Var}\left(Y_{i}\right)=\lambda_{i 1}^{2} \operatorname{Var}\left(F_{1}\right)+\lambda_{i 2}^{2} \operatorname{Var}\left(F_{2}\right)+(1)^{2} \operatorname{Var}\left(e_{i}\right)=\lambda_{i 1}^{2}+\lambda_{i 2}^{2}+\partial_{i}^{2} \\
\operatorname{Var}\left(Y_{i}\right)=\lambda_{i 1}^{2}+\lambda_{i 2}^{2}+\partial_{i}^{2}
\end{gathered}
$$

If there are $n$ variables and $m$ factors, the matrix expression of the subject is as follows:

$$
\begin{gathered}
X_{1}=\lambda_{11} F_{1}+\lambda_{12} F_{2}+\ldots+\lambda_{1 m} F_{m}+e_{1} \\
X_{2}=\lambda_{21} F_{1}+\lambda_{22} F_{2}+\ldots+\lambda_{2 m} F_{m}+e_{2} \\
X_{n}=\lambda_{n 1} F_{1}+\lambda_{n 2} F_{2}+\ldots+\lambda_{n m} F_{m}+e_{n} \\
{\left[\begin{array}{c}
X_{1} \\
\vdots \\
\vdots \\
X_{n}
\end{array}\right]_{n \times 1}=\left[\begin{array}{cccc}
\lambda_{11} & \cdots & \cdots & \lambda_{1 m} \\
\vdots & \ddots & & \vdots \\
\vdots & & \ddots & \vdots \\
\lambda_{n 1} & \cdots & \cdots & \lambda_{n m} \\
X_{n \times 1} & =A_{n \times m} F_{m \times 1}+e_{n \times 1}
\end{array}\right]_{m \times 1}\left[\begin{array}{c}
F_{1} \\
\vdots \\
F_{n \times 1}
\end{array}\right]_{n \times 1}+\left[\begin{array}{c}
e_{1} \\
\vdots \\
\vdots \\
e_{n}
\end{array}\right.}
\end{gathered}
$$

If the factors fully describe the observed variables, then it is possible to write:

$$
\begin{gathered}
e_{1}=e_{2}=e_{3}=0 \Rightarrow \sigma_{1}^{2}=\sigma_{2}^{2}=\sigma_{3}^{2}=0 \\
X_{n \times 1}=A_{n \times m} F_{m \times 1}
\end{gathered}
$$


After determining the factors, it is necessary to design the Analytical Hierarchical Process (AHP) and make comparisons between the various decision options. Therefore, a set of matrices, which numerically measures the relative importance of the indices relative to each other and each decision option, is measured according to the indices relative to the other options. This is carried out by making paired comparison between the decision elements. To do this, the $i$-th indices are often compared to the $j$-th indices (Table 1).

Table 1
\begin{tabular}{|l|c|}
\hline Judgment & Vairwise comparison scale \\
\hline \hline \multirow{2}{*}{ Extremely important } & 9 \\
\hline \multirow{2}{*}{ Very strongly more important } & 8 \\
\hline \multirow{2}{*}{ Strongly more important } & 7 \\
\hline \multirow{2}{*}{ Moderately more important } & 6 \\
\hline Equally important & 5 \\
\hline
\end{tabular}

Initially, the weight of factors derived from factor analysis was calculated by means of pair comparison matrix and the integration of expert group views through the geometric mean (Table 3). An incompatibility rate of less than 0.1 represents a good match, otherwise, it should be re-evaluated in comparisons. Subsequently, coefficient of priority of each factor was obtained in four criteria of proactive, preventive, predictive and emergency maintenance strategy by the paired matrix in the Expert Choice software (Table 3). Weight of the factors is then calculated in accordance with Table 4. At this stage, in order to rank the decision matrix criteria, we must multiply the weight of each factor by the weight of the options until its final weight is obtained. Final weight of each option that has the highest value is selected as appropriate option.

\section{Results and discussion}

By entering the criteria related to maintenance strategy, the following results were obtained in the SPSS software and the factor analysis.

Figures showed in the table above represent the specific values, and the higher the absolute value of a particular parameter value in a factor, the greater the allocation of this parameter to that particular factor. In some cases, however, values are close to several factors, and assigning the parameter to a particular factor causes some data to be lost. For example, there are hesitations whether to allocate the wage repair parameter to factors 2 and 3. Therefore, for better interpretation, as well as better determination of number of factors, the invariant invariance with the Vari-max criterion is used to simplify the inverse matrix columns. Results are presented in Table 5 . After rotation of factors, allocation of parameters to the factors is more accurate and shows lower amount of errors. By the

Table 2 Matrix of pair-wise comparison of factors

\begin{tabular}{|l|c|c|c|c|c|c|}
\hline & Factor 1 & Factor 2 & Factor 3 & $\ldots$ & Factor $\boldsymbol{n}$ & Eigenvector \\
\hline Factor 1 & $\mathrm{f} 11$ & $\mathrm{f} 12$ & $\mathrm{f} 13$ & $\ldots$ & $\mathrm{f} 13$ & $\mathrm{v} 1$ \\
\hline Factor 2 & $\mathrm{f} 21$ & $\mathrm{f} 22$ & $\mathrm{f} 23$ & $\ldots \ldots$ & $\mathrm{f} 23$ & $\mathrm{v} 2$ \\
\hline$\ldots \ldots .$. & $\ldots \ldots$ & $\ldots \ldots$ & $\ldots \ldots$ & $\ldots \ldots$ & $\ldots \ldots$ & $\ldots \ldots$ \\
\hline Factor $n$ & $\mathrm{fn} 1$ & $\mathrm{fn} 2$ & $\mathrm{fn} 3$ & $\ldots \ldots$ & $\mathrm{fn} 3$ & $\mathrm{v} n$ \\
\hline
\end{tabular}

Table 3 Matrix of pair-wise comparison of criterion for each factor

\begin{tabular}{|c|c|c|c|c|c|}
\hline Factor $n$ & Criterion 1 & Criterion 2 & ...... & Criterion $m$ & Eigenvector \\
\hline Criterion 1 & A11 & $\mathrm{A} 12$ & $\ldots \ldots$ & $\mathrm{A} m 1$ & Ven 1 \\
\hline Criterion 2 & $\mathrm{~A} 21$ & $\mathrm{~A} 22$ & $\ldots \ldots$ & $\mathrm{A} m 1$ & Ven2 \\
\hline .... & $\ldots .$. & $\ldots .$. & $\ldots \ldots$ & ........ & $\ldots \ldots$ \\
\hline Criterion $\boldsymbol{m}$ & $\mathrm{Am} 1$ & $\mathrm{~A} m 2$ & $\ldots \ldots$ & $\mathrm{Amm}$ & Vc $n m$ \\
\hline
\end{tabular}

Table 4 Matrix of pair-wise comparison of weight of each factor on the basis of criteria

\begin{tabular}{|l||c|c|c|c|}
\hline \multicolumn{1}{|c||}{} & Factor 1 & Factor 2 & $\ldots \ldots .$. & Factor $\boldsymbol{n}$ \\
\hline \hline Criterion 1 & V11 & V12 & $\ldots \ldots$ & $V 1 n$ \\
\hline Criterion 2 & V21 & V22 & $\ldots \ldots$ & $V 2 n$ \\
\hline$\ldots$. & $\ldots \ldots$. & $\ldots \ldots$ & $\ldots \ldots$ & $\ldots \ldots$ \\
\hline Criterion $\boldsymbol{m}$ & $V m 1$ & $V m 2$ & $\ldots \ldots$ & $V m n$ \\
\hline
\end{tabular}


Table 5 Factor analysis results before and after inversion rotation

\begin{tabular}{|l||c|c|c|c|c|c|}
\hline \multicolumn{1}{|c|}{} & \multicolumn{3}{|c|}{ Before rotation of factors } & \multicolumn{3}{c|}{ After rotation of factors } \\
\hline \hline Parameter & Factor 1 & Factor 2 & Factor 3 & Factor 1 & Factor 2 & Factor 3 \\
\hline Fuel cost & 0.956 & -0.233 & -0.147 & 0.954 & 0.247 & -0.147 \\
\hline Lubrication cost & 0.949 & -0.248 & -0.155 & 0.952 & 0.237 & -0.157 \\
\hline Cost of spare parts & 0.529 & 0.744 & -0.199 & 0.189 & 0.876 & 0.259 \\
\hline Wage repair & 0.414 & $\mathbf{0 . 6 3 3}$ & $-\mathbf{0 . 6 5 2}$ & 0.077 & 0.974 & -0.206 \\
\hline Reliability & 0.864 & -0.381 & -0.251 & -0.679 & -0.497 & -0.496 \\
\hline Annual Function & 0.99 & -0.023 & -0.033 & 0.918 & 0.368 & 0.065 \\
\hline Depreciation & 0.991 & -0.093 & -0.071 & 0.941 & 0.333 & -0.003 \\
\hline Equipment & 0.956 & -0.233 & -0.147 & 0.954 & 0.247 & -0.141 \\
\hline Stagnation & 0.856 & -0.345 & 0.321 & 0.951 & -0.109 & 0.197 \\
\hline Period of repair & 0.438 & 0.708 & 0.545 & 0.194 & 0.449 & 0.867 \\
\hline Number of failures & 0.736 & -0.502 & 0.446 & 0.912 & -0.34 & 0.214 \\
\hline Training & 0.81 & 0.313 & 0.155 & 0.644 & 0.472 & 0.374 \\
\hline Education & $0.313-$ & 0.272 & 0.902 & -0.298 & -0.35 & 0.88 \\
\hline
\end{tabular}

Table 6 Classification of factors

\begin{tabular}{|l||l|}
\hline Factor $\mathbf{1}$ & $\begin{array}{l}\text { - fuel cost, lubrication cost, reliability, annual function, depreciation, equipment, stagnation, number } \\
\text { of failures, training }\end{array}$ \\
\hline Factor $\mathbf{2}$ & - cost of spare parts, wage repair \\
\hline Factor $\mathbf{3}$ & - education, period of repair \\
\hline
\end{tabular}

Table 7 Weight of factors in maintenance strategies

\begin{tabular}{|l||c|c|c|}
\hline Criteria & Factor 1 & Factor 2 & Factor 3 \\
\hline \hline EM & 0.053 & 0.658 & 0.055 \\
\hline PM & 0.316 & 0.155 & 0.125 \\
\hline PdM & 0.316 & 0.11 & 0.175 \\
\hline PAM & 0.316 & 0.078 & 0.644 \\
\hline
\end{tabular}

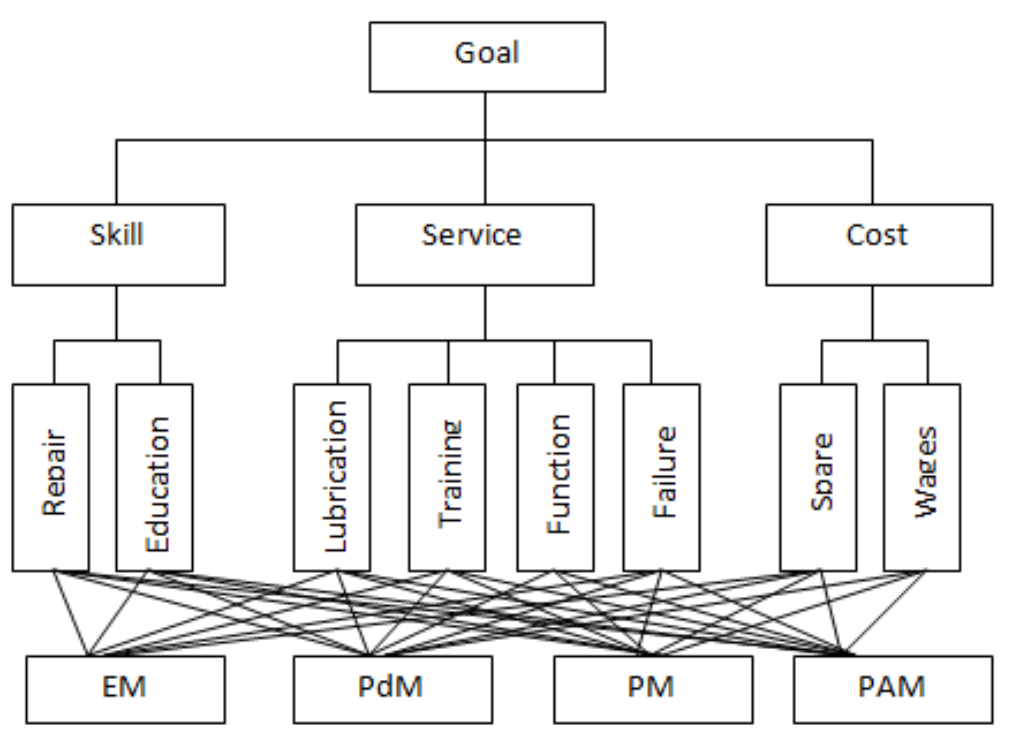

Fig. 2 Flowchart of AHP for selection of the best maintenance strategy breakdown of the parameters allocated to each factor, following results were obtained (Table 5).

In regards to the parameters in each factor, factors are labelled. They were called respectively; factor 1 - service, factor 2 - maintain cost, factor 3 - skill.

By determining the purpose and defining the factors in the Expert Choice software, the weight of each factor was determined (Fig. 3).

Considering the weight of factors, service factor is the most important in choosing a maintenance strategy; followed by skill and cost factors. Subsequently, the weight of the factors in the criteria was determined.

Therefore, it can be said that factor 1 has the same effect on the preventive, predictive and proactive strategies that are included in the planned programs, because service is one of the main factors of these three maintenance operations. Also, the weights of factor 2 in emergency maintenance (EM) and factor 3 in proactive maintenance (PAM) are greater. Finally, using the 


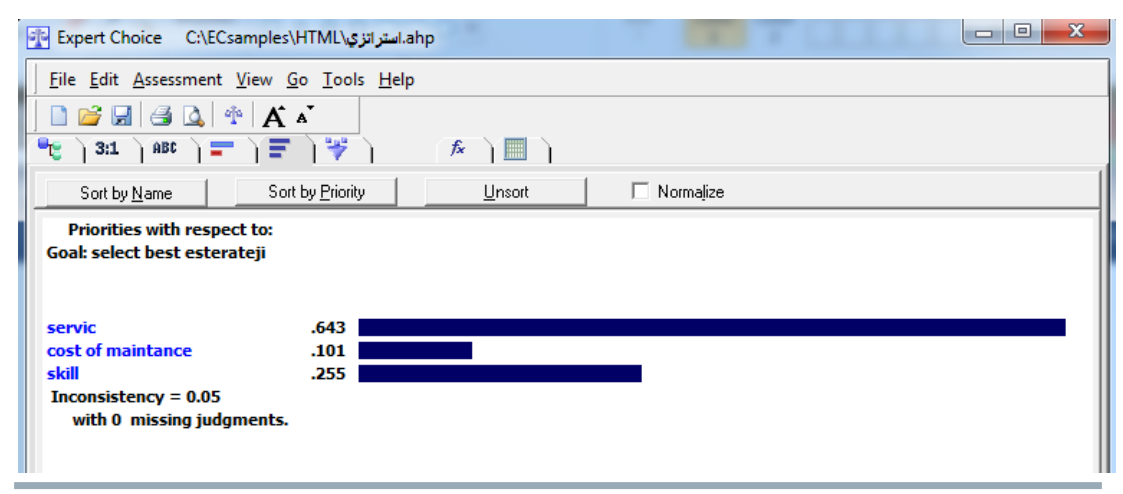

Fig. 3 Weight of each factor

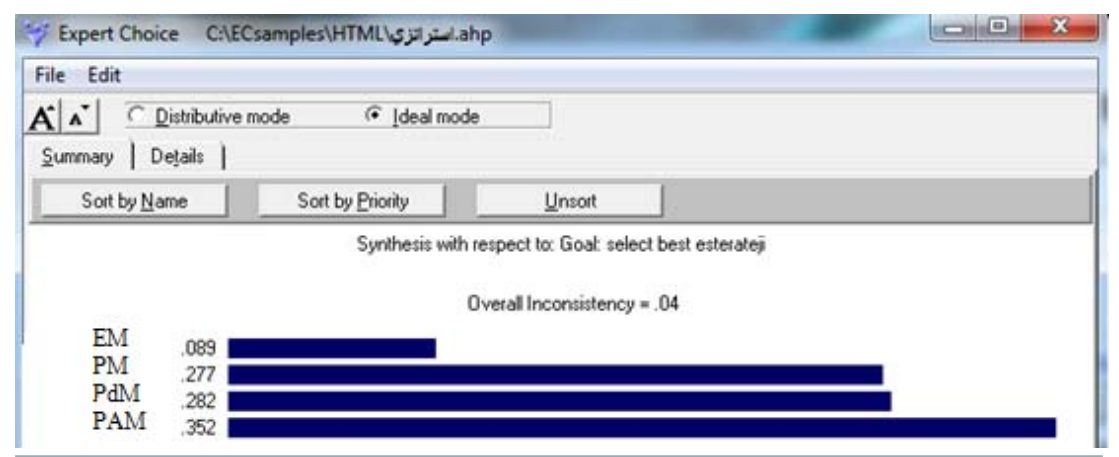

Fig. 4 The final weight of the examined strategies

weight of the factors and the weight of each factor in the criteria, we arrive at the final weight of each of the strategies.

The weight of the preventive, predictive, and proactive strategies is close, due to the alignment of the goals of these strategies that are almost complementary to each other. However, as the proactive strategies (PAM) attempt to root out causes of failures, they are preferable to the others, as was confirmed by calculations and studies. Therefore, the proactive strategy is chosen as the most appropriate. According to Javadian and Hashemi (2013), proactive strategy is actually a combination of preventive and predictive strategies aimed at improving the operating conditions of machines, reducing their need for implementation of the program and completely eliminating the causes of failures.

\section{Conclusions}

In this paper, firstly, by combining factor analysis and AHP, factors essential for tractor maintenance were identified. With design of the hierarchical analysis tree, options were evaluated and finally a maintenance strategy was selected. Particularly, results indicate that a push towards modernization of maintenance strategies in the Urmia region is necessary.

In order to be certain of the superiority of the proactive approach to preventive, predictive and emergency methods, it is essential that each of these management systems are applied in the Urmia region so that the results of the paper can be compared statistically with empirical data.

\section{References}

AFSHARNIA, F. - ASOODAR, M. A. - ABDSHAHI A. 2013. Regression analysis and modeling of failure rate and its effective factors on tractors in some cities of Khuzestan province. In Journal of Agricultural Engineering, vol. 36, no. 2, pp. 58-49.

BARTHOLOMEW, L. 1981. Farm machinery costing under inflation. In Transaction of ASAE, vol. 24, no. 1, pp. 98-101.
BEHZAD, M. - GHASEMI, A. - EBRAHIMI, A. ROUHANI A. 2007. Preventive maintenance at water pumping stations. In W. W. C. E., vol. 58, pp. 10-18.

DAHUNSI, O. A. 2008. Spectrometric Oil Analysis - an Untapped Resource for Condition Monitoring. Mechanical Engineering Department, Federal University of Technology Akuer, Undo State, Nigeria.

EXNER, K. - SCHNURMCHER, C. - ADOLPHY, S. - STARK, R. 2017. Proactive maintenance as success factor for use-oriented ProductService Systems. In Procedia CIRP 64, pp. 330-335.

JAFARI, K. - MAHVI DIANI, M. 2003. A survey on tractor exploitation pattern in Kerman province. In Quarterly Journal of Agricultural Economics and Development, vol. 37, pp. 25-31.

JAVADIAN, M. - HASHEMI, M. 2013. Proactive maintenance for metal molds based on multiplication. In Engineering \& Manufacturing Journal, vol. 25, pp. 209-213. KHODABAKHSHIAN KARGAR, R. - SHAKERI, M. - BARADRAN, J. 2008. Preventive maintenance engineering and monitoring of the situation in road construction machines. In $5^{\text {th }}$ International Conference on Maintenance. Iran Maintenance and Maintenance Association. Tehran.

MIRZAKHANI, H. 2004. Performance analysis of storage planning system in Khuzestan Cement Company. Available at: http://dpe. ir

MOUSAVI POUR, A. - SHEIKH DAVOODI, M. J. - GHANIAN, M. - SAEEDI, N. 2012. Economical comparison of usually urgent oil check and oil monitoring methods for repair and maintenance of sugarcane harvesters. In Journal of Agricultural Engineering, vol. 35, no. 1, pp. 15-27.

RICHARDS, L. 1983. Factor Analysis. $2^{\text {nd }}$ Edition. Lawrence Erlbaum Associate Inc.

SAY, S. M. - SUMER, S. K. 2011. Failure rate analysis of cereal combined drills. In African Journal of Agricultural Research, vol. 6, pp. 1322-1329.

SHIRMOHAMMADI, A. 2002. TPM maintenance and repair. $1^{\text {st }}$ Edition, Arkan Inc.

ZASADZIEŃ, M. - MIDOR, K. 2018. Statistical process control as a failure removal improvement tool. In Acta Technologica Agriculturae, vol. 23, pp. 124-129. 